\title{
Child Psychologist's 5 Keys for a Simple Digital Family Rules Contract
}

\author{
Adam Pletter* \\ 4Clinical Psychologist in Private Practice, USA
}

Submission: September 13, 2017; Published: September 27, 2017

*Corresponding author: Adam Pletter, Clinical Psychologist in Private Practice, Democracy Medical Center, The George Washington University, 6312 Democracy Blvd Bethesda, Maryland, USA, Tel: (301) 530-0077, Email: info@iparent101.com

\section{Short Communication}

When parents get together we often commiserate about universal parenting struggles based on our children's current phase of development. We all know the basics: sleeping, eating, potty training, homework, driving, dating, and the list go on, capped off with the empty nest struggle (if we are lucky!) And as the expression goes, little kids-little problems, big kids-big problems. But what happens when you apply that principal to the digital world? From what I hear on the sidelines at field hockey, in my clinical office and at digital parenting workshops, the universal parenting struggles remain, but are complicated as digital developmental stages have blurred the expectations.

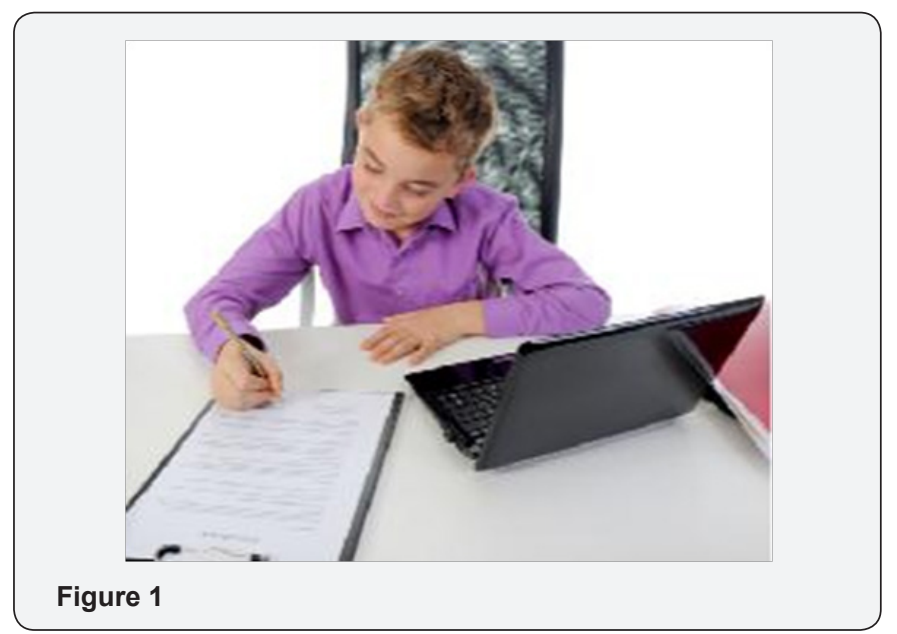

The basic tenets of parenting to nourish, teach and protect our offspring have not changed, but the landscape has as we struggle to manage the digital takeover of our families. So let's rewind 15 years to the first few years of my private practice when the parenting questions often centered around adjusting family rules and expectations for behavior. A common theme I heard then and hear in my office today is that the child is able to manage himself in school or other structured environments where the rules are clearly defined and enforced in a predictable way; however, at home, this child struggles and battles incessantly against parent's wishes. Yes, there are many factors, but my clinical interventions always include understanding how the same child is better able to regulate himself within the provided school structure. Home life should be more relaxed and less structured than a school, but firming up the rules and expectations and striving to be more consistent helps all children learn and grow within the acceptable boundaries (Figure 1).

So, while the influx of digital devices complicates parental expectations, family rules should still be thoughtful, clear and enforceable...just like all other parenting decisions. So let's review the basics of what should be considered to be included in your Digital Family Rules Contract.

\section{This is an adult device}

The smart phone, tablet, or iPod touch that you are handing to your child is designed for adults and, out of the box, is set up for adults-not children. Be honest with yourself that by giving your child the adult device you are inviting them into the adult digital world. Think about that-same access to content and connections around the world that you have. Is that what you are intending? If so, I'm surprised, but okay. If not, take the time to set up the basic parental controls and lay out the rules for having such an incredible gadget. It's akin to the parent having a contract with their cell phone provider where there are clear rules and guidelines that are agreed upon before access is allowed. In turn, I recommend having the Family Rules Contract to be written and clear. By the way, it is developmentally appropriate for children and teenagers to test limits and push the boundaries of what is allowed. If the starting place is everything is allowed unless there is a problem, the parent will be locked into a reactive stance, playing catch up and putting out fires as they arise.

\section{Specific Guidelines of where and when your child's device can be used should be clear}

I am talking about the basics here. What are the time limits for the device's use? Does the device get stowed somewhere 
at night (preferably not in their bedroom!)? How about in the morning, is access granted at a certain time? How about in the car? On sleepovers? All of these situations (and more) will vary depending on your family's values and age of your child. There is no one answer, but my clear suggestion is for the parents to decide and then write it down so it can be referenced when limits are tested. As the child responsibly follows the agreed upon 'terms of service', he/she will be granted more developmentally appropriate access. In turn, a positive reinforcement cycle is established, wherein he or she will be motivated to continue to follow established rules.

\section{All Passwords should be private and shared with parents}

There, I said it! Yes, passwords should not be shared with even best friends (trust me I have heard the drama), but need to be shared with parents in order to build trust and healthy communication. Let me clarify: I am not encouraging parents to have access in order to snoop, stalk, or otherwise interfere with the child's online life. Seriously, do not do that; however, by having the passwords shared, you are helping the child slow down and think about what they are posting and doing online. It is critically important for young people with still developing regulatory skills to learn how to pause and think. Knowing that their parent may see their post encourages this skill and fosters the healthy parent/child dialogue as they mature. Again, I tell all parents in my office to be up front about having the passwords, but seldom discuss anything they see on their child's social media, unless there is a safety concern. The point here is to have the child practice making healthy choices online while they are still under our supervision-similar to learning to drive while a parent is sitting quietly in the passenger seat.

\section{Parents should require permission/dialogue before child downloads anything}

Yup, even those free games that your child hears about from the older kids on the bus. If you are following along so far this should follow that I am promoting the child/parent dialogue so children are learning how to manage the digital world. It's not about stopping the child from downloading, but rather for the child to pause and talk to the parent about what he wants and then parents making a somewhat informed decision about the app. This should sound familiar for parents. For example, if a 9 year old comes home from school with plans of buying a bee bee gun with his allowance money, most parents would want to talk about that purchase. The answer may be, "sure, let's go to the store and get the best one we can." Or some parents may say, "not yet, but let's talk about it when you are older," or some parents may just say "no." In the digital world, this communication should be similar. I typically recommend the "yes, when..." response to most of these requests. Yes, you can have this app (after looking it up in the App store or CommonSense Media) when you are more respectful, or when you are older. Reality is whatever the app is, your child will likely have it at some point, I want the child to be empowered to help himself get the app by demonstrating the good behavior. As a digital parent, it is also helpful to know what apps are on the child's phone so your 10 year old is not on an anonymous messenger app (e.g., KIK) , talking to strangers.

\section{When child acts older, he will be treated older with clear and predictable levels of digital access}

This again, should follow as the child makes better choices and shows the parent that he can handle more mature subject matter and follow the family rules without tantruming (just like in any other parenting decision) he will get more access. Do you let your 7 year old watch PG-13 movies? How about rated R? I bet some of you do and it depends on the movie content and how your child handles it afterward. If your child doesn't sleep for a month because she is scared of snakes after watching Indiana Jones, you would likely steer her away from movies with someone trapped in a pit with snakes wiggling and hissing up their legs. Right? My push here is for the child to be empowered to change their behavior to get more of what they want. And for parents to offer higher levels of access after the child shows more mature (by comparison) behavior. This is a great way to motivate your child to act older since over time they will work for higher levels of access which are predictable.

So there you have it. The five keys for setting up your Digital Family Rules Contract to teach your children to be safe and savvy digital citizens over time. You may be wondering if I left something out? I surely did (sorry, I won't call you Shirley) and that is this: the contract is a roadmap for our children to follow so they are better equipped to manage their ever expanding digital world. But it is also essential that we, the parents, follow the basic rules as well. If you have a rule that there should be no texting while in the car, you should not text at the traffic light. If you have a rule not to have iPhones at the kitchen table, be sure not to have yours while you eat your cereal. Like all other parenting decisions, we are modeling what our children will learn to do. Where'd they learn to do this stuff? They learned it by watching us! 
